\title{
Review
}

Neonatology

Neonatology 2015;107:220-223

DOI: $10.1159 / 000369119$
Received: June 19, 2014

Accepted after revision: October 14, 2014

Published online: February 12, 2015

\section{Innate Hypothermia after Hypoxic Ischaemic Delivery}

\author{
Dulip Jayasinghe \\ Nottingham Neonatal Service, Nottingham University Hospitals NHS Trust, Nottingham, UK
}

\author{
Key Words \\ Acidosis · Adaptation at birth · Asphyxia - Body \\ temperature $\cdot$ Hypothermia $\cdot$ Hypoxia $\cdot$ Ischaemia . \\ Thermogenesis
}

\begin{abstract}
The focus of this review is to collate the literature on the phenomenon of impaired thermal adaptation after hypoxic ischaemic ( $\mathrm{HI})$ delivery often culminating in hypothermia. This phenomenon appears different in severity and duration to a spontaneous postnatal fall in temperature observed after normal delivery. The original observation and contemporary descriptions of the temperature response to $\mathrm{HI}$ are described and a mechanism of action is proposed that may be utilised as a novel biomarker for $\mathrm{HI}$.

(c) 2015 S. Karger AG, Basel
\end{abstract}

We are born naked, wet and hungry. Without intervention, the inevitable consequence of this state is newborn hypothermia. Historically, infants who have experienced hypoxic ischaemia (HI) during delivery frequently experienced hypothermia [1]. Whilst there is a large body of literature describing the evidence base supporting therapeutic hypothermia after HI encephalopathy, there is scant literature on how antenatal HI impairs human newborn thermal adaptation. The purpose of this review is to collate the evidence around impaired thermal adaptation after HI delivery - a maladaptation sometimes sufficient to result in hypothermia. (c) 2015 S. Karger AG, Basel

$1661-7800 / 15 / 1073-0220 \$ 39.50 / 0$
Prior to birth, the fetus is typically $0.5^{\circ} \mathrm{C}$ warmer than the mother [2,3] and rapidly cools [1] unless dried and wrapped. Heat is lost to the environment by evaporation, convection, conduction, and radiation, culminating in up to $10 \%$ of infants $[4,5]$ experiencing transient hypothermia soon after birth [6]. The fall in temperature seen after normal delivery can be minimised by appropriate care practices such as drying and wrapping [1].

The normal adaptive response to cold air exposure after birth is associated with a rise in oxygen consumption [7] from the activation of brown adipose tissue $[8,9]$. Brown adipose tissue is rich in mitochondria which consume oxygen, generating metabolic heat through uncoupled aerobic respiration - non-shivering thermogenesis. When exposed to a heat-losing environment, normal term infants are able to double their oxygen consumption to mount a metabolic thermogenic response [10, 11]. Hypothermia occurs when heat loss to the environment exceeds non-shivering thermogenesis. At particular risk of impaired thermal adaptation are infants who have experienced HI during labour and delivery. This deficit in thermogenesis may be related to the effects of $\mathrm{HI}$ delivery and require external heating to compensate. Hence, even with adequate attempts to minimise heat loss, in the absence of external heating hypothermia may result.

Hypothermia following delivery has been observed and documented in the early literature [12]. In 1958 Burnard and Cross [13] systematically studied the temperature profile of asphyxiated infants, using 'a failure to achieve spontaneous respiration by $3 \mathrm{~min}$ ' as a definition

\section{KARGER 125}

E-Mail karger@karger.com www.karger.com/neo
Dr. Dulip Jayasinghe, $\mathrm{MBCHb}, \mathrm{MD}$

Neonatal Intensive Care Unit, Nottingham City Campus

Nottingham University Hospitals NHS Trust

Hucknall Road, Nottingham NG5 1PB (UK)

E-Mail dulip.jayasinghe@ nuh.nhs.uk 


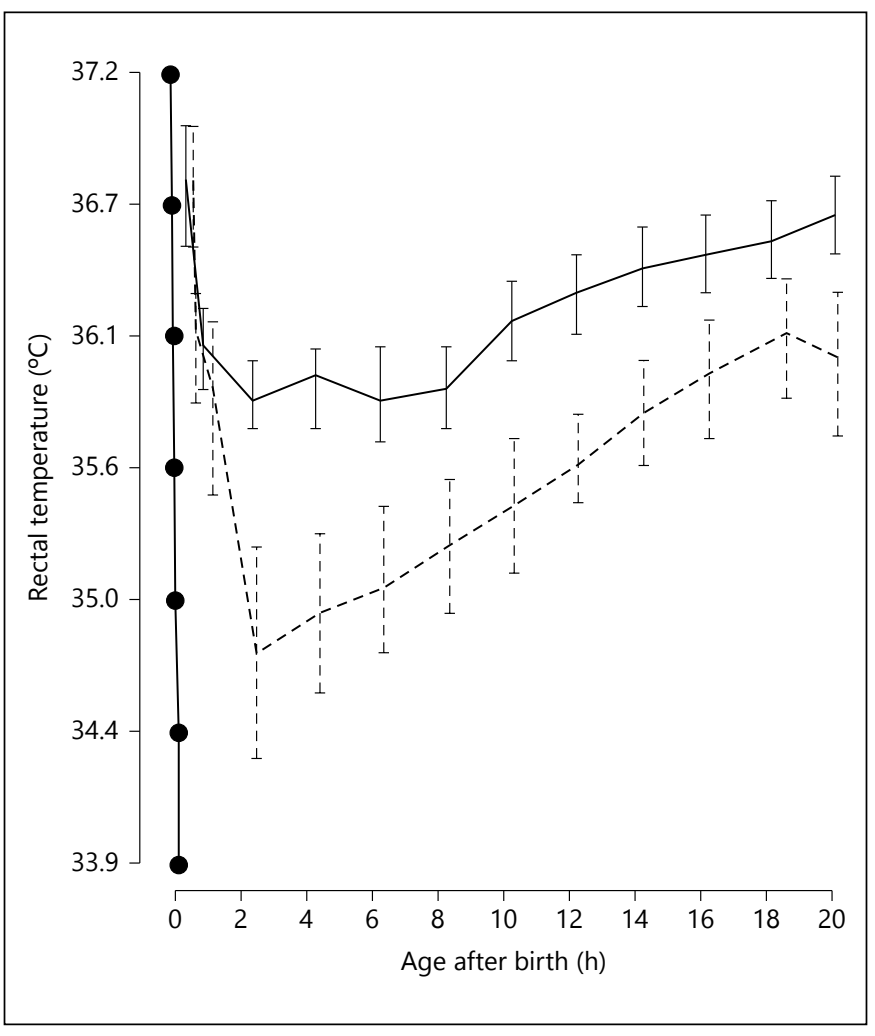

Fig. 1. Mean rectal temperatures after normal birth and after birth asphyxia (defined as failure to establish respiration within $3 \mathrm{~min}$ ). The vertical lines are the $95 \%$ confidence limits of the means. Continuous line: $\mathrm{n}=53$ babies (normal delivery); broken line: $\mathrm{n}=15$ babies (asphyxia, no pethidine). Redrawn from Burnard [13] with permission.

of asphyxia. They observed that under the same environmental conditions as non-asphyxiated infants, the asphyxiated infants had lower rectal temperatures, taking $18 \mathrm{~h}$ to achieve similar temperatures to the normal infants (fig. 1). They speculated that the observed fall in temperature was related to reduced oxygen consumption and heat generation following the asphyxial insult [14]. No details were documented on the care procedures and some of the asphyxiated infants may have received supplemental unheated and unhumidified ambient oxygen, contributing to their fall in temperature. Over the subsequent 50 years disparate studies have reiterated this observation in human newborn infants [15], and recently in low-resource settings $[16,17]$. The studies are difficult to compare and, crucially, they differ in the different definitions of asphyxia or perinatal HI. The original definition of asphyxia used by Burnard and Cross [13] would not now be deemed evidence of perinatal hypoxia [18], but contemporary studies have used definitions that are consistent with cooling trial inclusion criteria. Despite these differences in case definition similar patterns emerge.

A significant, widely cited paper on thermal adaptation, published in Biology of the Neonate, was the work of Brück et al. [19]. The authors described infants born by difficult delivery who, on exposure to cold, were unable to achieve the doubling of heat production seen in neonates after uncomplicated delivery [20]. Other authors found that the oxygen consumption of a group of asphyxiated infants (Apgar scores 1-7 at 1 and $5 \mathrm{~min}$ ) was lower than that of non-asphyxiated infants when examined at room temperature $\left(24^{\circ} \mathrm{C}\right)$ and remained lower for at least $72 \mathrm{~h}$ [21]. When challenged with a 1-hour fall in environmental temperature there was a rise in oxygen consumption in most asphyxiated infants, but not to the magnitude seen in normal infants exposed to the same challenge, suggesting that oxygen consumption was lower than expected in the asphyxiated infants and possibly explaining a persistently low temperature in the first $24 \mathrm{~h}$. Similarly, Schubring [22] showed that when the oxygen consumption and temperatures of 13 resuscitated infants (with Apgar scores $<7$ ) were compared with 31 term infants with normal Apgar scores, a significant difference in the oxygen consumption was noted until $130 \mathrm{~min}$ and in rectal temperature until $75 \mathrm{~min}$.

It is also interesting to note that impaired heat generation may also precede delivery. The following studies suggest that heat loss from infants who have experienced a period of acidosis or hypoxia during labour have reduced heat generation and hence heat loss. In the 30 min prior to delivery, scalp heat loss was correlated with umbilical artery $\mathrm{pH}$, suggesting that heat production may be lower in those who were acidotic [23]. A difference in heat loss was also noted in infants who were not acidotic or required resuscitation [24] and heat loss from the back of newborn infants, overlying one site of brown adipose tissue, was correlated with umbilical artery $\mathrm{PaO}_{2}$.

The most recent illustrations of impaired thermal adaptation are from neuroprotective hypothermia trials. One study [16] noted a fall in rectal temperature in the control group, attaining normothermia at a mean age of $15 \mathrm{~h}$ (fig. 2), and a recent study [17] reported hypothermia for $8 \mathrm{~h}$ in control infants [Thayyil, pers. commun.]. During a randomised hypothermia trial it was noted by one cooling centre that the cooling blanket was being used to warm the baby for the majority of the $72 \mathrm{~h}$ [25]. Another centre offering therapeutic hypothermia noted that infants with more severe encephalopathy had a low- 
Fig. 2. Mean rectal temperature in standard care $(n=15)$ and therapeutic hypothermia $(\mathrm{n}=21)$ groups during the first $80 \mathrm{~h}$ after randomisation. Infants were randomised when the Apgar score at $5 \mathrm{~min}$ had been less than 6 and the Thomson score at $30 \mathrm{~min}$ to $3 \mathrm{~h}$ after birth was higher than 5 . Mean age at randomization was $112 \mathrm{~min}$. Error bars $=$ SD. Reproduced from Robertson [16] with permission.

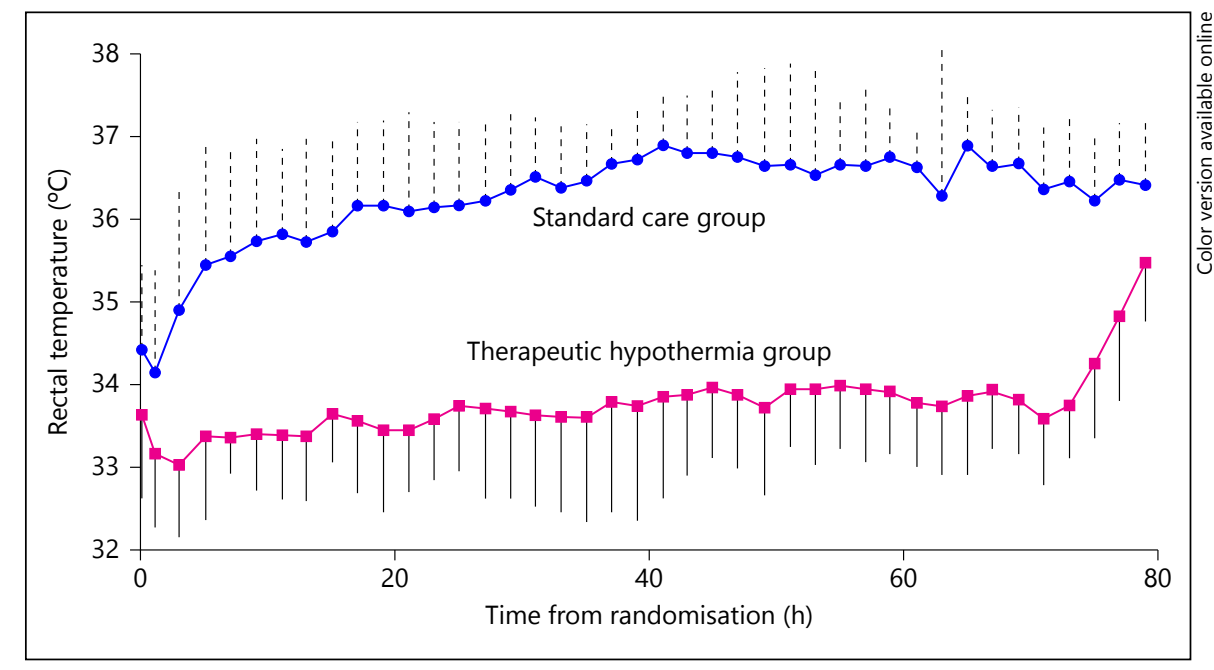

er temperature prior to the induction of active cooling [26].

In contradistinction, there is evidence that temperature instability and pyrexia is associated with the development of cerebral palsy in symptomatic [27] and asymptomatic infants [28]. HI that goes unrecognised prior to birth may lead to a failure in heat generation after birth and consequent labile temperature, later manifesting as cerebral palsy. Similarly, hyperthermia after perinatal HI encephalopathy is recognised as a predictor of poor outcome in the large cooling trials $[29,30]$, suggesting that a period of low temperature after HI may be a protective physiological response.

The failure of the normal thermal adaptive response has been employed in the delivery of therapeutic neuroprotective hypothermia. The neuroprotective trials have been conducted using active cooling. However, passive cooling is used in the peri-transfer period [31-33] and to initiate and maintain mild hypothermia [34], exploiting the transient hypothermia experienced by infants after HI delivery. Impaired heat production may not be universal in all infants after HI delivery but is a component of multi-organ injury seen in the majority $[35,36]$ of babies with $\mathrm{HI}$ encephalopathy. Infants experiencing endogenous cooling due to reduced heat production capability in the control arm of trials [16] might also dilute the expected trial effect of active neuroprotective hypothermia.

The evidence substantiating the original finding of Burnard and Cross [13] of impaired thermal adaptation is compelling but not conclusive. The challenge is to replicate the original findings in a population of infants after $\mathrm{HI}$ delivery, using contemporary definitions of $\mathrm{HI}$ deliv- ery [18]. A full characterisation of the phenomenon would require the use of calorimetry to quantify the heat transfer to the environment. The greatest challenge is to identify a relationship between thermal maladaptation and encephalopathy following HI delivery [37].

A fall in temperature after birth has been described in the early literature and can be minimised with simple interventions. Studies over the last 50 years have described temperature profile or heat production after HI delivery that differs from that after uncomplicated delivery, despite different definitions of HI, many of which would not be considered valid today. The term innate hypothermia is used speculatively to describe hypothermia that is not a consequence of environmental conditions or inadequate care practices but an obligate, evolved protective response to $\mathrm{HI}$ delivery. Hypothermia following hypoxia is seen in other immature and mature newborn mammals [38] and may provide an adaptive survival benefit [39] after mild or moderate HI delivery. Neuroprotective hypothermia may not date back to the late 1940s [40] but to a common mammalian ancestor [41] 96 million years ago.

In summary, impaired heat production and consequent lower body temperature after HI delivery appears to be a measurable phenomenon with a plausible mechanism of action that warrants further investigation and may serve as a biomarker for the severity of insult.

\section{Acknowledgements}

I am most grateful for the helpful comments and suggestions offered by Dr. A. Leslie, Dr. Ward-Platt and Dr. H. Budge. 


\section{References}

1 Dahm LS, James LS: Newborn temperature and calculated heat loss in the delivery room. Pediatrics 1972;49:504-513.

$>2$ Alexeev: Ueber die Temperatur des Kindes im Uterus. Arch Gynakol 1876;10:141-144.

$\checkmark 3$ Wood C, Beard RW: Temperature of the human foetus. J Obstet Gynaecol Br Commonw 1964;71:768-769.

4 Johanson R, Spencer A: Temperature changes during the first day of life in the North Staffordshire Maternity Hospital. Midwifery 1992;8:82-88.

$>5$ Takayama JL, Teng W, Uyemoto J, Newman TB, Pantell RH: Body temperature of newborns: what is normal? Clin Pediatr 2000;39: 503-510.

6 Johanson RB, Spencer SA, Rolfe P, Jones P, Malla DS: Effect of post-delivery care on neonatal body temperature. Acta Paediatr 1992; 81:859-863.

$>7$ Hill JR, Rahimtulla KA: Heat balance and the metabolic rate of new-born babies in relation to environmental temperature; and the effect of age and of weight on basal metabolic rate. J Physiol 1965;180:239-265.

$>8$ Dawkins MJ, Scopes JW: Non-shivering thermogenesis and brown adipose tissue in the human new-born infant. Nature 1965;206: 201-202.

$\checkmark 9$ Symonds ME, Pope M, Budge H: Adipose tissue development during early life: novel insights into energy balance from small and large mammals. Proc Nutr Soc 2012;71:363370.

$>10$ Adamson SK Jr, Gandy GM, James LS: The influence of thermal factors upon oxygen consumption of the newborn human infant. J Pediatr 1965;66:495-508.

11 Hey EN: The relation between environmental temperature and oxygen consumption in the new-born baby. J Physiol 1969;200:589-603.

12 Dunn PM: Professor Pierre Budin (18461907) of Paris, and modern perinatal care. Arch Dis Child Fetal Neonatal Ed 1995; 73:F193-F195.

$>13$ Burnard ED, Cross KW: Rectal temperature in the newborn after birth asphyxia. Br Med J 1958;2:1197-1199.

$>14$ Brodie HR, Cross KW, Lomer TR: Heat production in new-born infants under normal and hypoxic conditions. J Physiol 1957;138: 156-163.

15 Brown JK, Purvis RJ, Forfar JO, Cockburn F: Neurological aspects of perinatal asphyxia. Dev Med Child Neurol 1974;16:567-580.
16 Robertson NJ, Nakakeeto M, Hagmann C, Cowan FM, Acolet D, Iwata O, et al: Therapeutic hypothermia for birth asphyxia in lowresource settings: a pilot randomised controlled trial. Lancet 2008;372:801-803.

17 Thayyil S, Shankaran S, Wade A, Cowan FM, Ayer M, Satheesan K, et al: Whole-body cooling in neonatal encephalopathy using phase changing material. Arch Dis Child Fetal Neonatal Ed 2013;98:F280-F281.

18 MacLennan A: A template for defining a causal relation between acute intrapartum events and cerebral palsy: international consensus statement. Br Med J 1999;319:1054-1059.

19 Brück K, Brück M, Lemtis H: Temperature regulation in the newborn infant. Biol Neonate 1961;3:65-119.

20 Brück K, Brück M, Lemtis H: Temperature regulation in newborn and premature infants after spontaneous and pathological delivery (in German). Geburtshilfe Frauenheilkd 1960;20:461-472.

21 Pribylova H, Znamenacek K: Oxygen consumption and other regulative mechanisms of energy metabolism in pathological states of the newborn. Biol Neonate 1969;14:133-141.

22 Schubring C: Temperature regulation in healthy and resuscitated newborns immediately after birth. J Perinat Med 1986;14:27-33

23 Rudelstorfer R, Simbruner G, Bernaschek G, Rogan AM, Szalay S, Janisch H: Heat flux from the fetal scalp during labor and fetal outcome. Arch Gynecol 1983;233:85-91.

24 Oya A, Asakura H, Koshino T, Araki T: Thermographic demonstration of nonshivering thermogenesis in human newborns after birth: its relation to umbilical gases. J Perinat Med 1997;25:447-454.

25 Massaro AN, Kadom N, Baumgart S, Tuschida T, Short BL, Chang T: Whole body cooling therapy: is it really a cooling mattress? Abstract Pediatr Acad Soc Annu Meet, Toronto, 2007.

26 Sant'Anna G, Laptook AR, Shankaran S, Bara $\mathrm{R}, \mathrm{McD}$ onald $\mathrm{S}$ a, Higgins RD, et al: Phenobarbital and temperature profile during hypothermia for hypoxic-ischemic encephalopathy. J Child Neurol 2012;27:451-457.

27 Nelson KB, Ellenberg JH, Nelson B, Elleitberg $\mathrm{H}$ : Neonatal signs as predictors of cerebral palsy. Pediatrics 1979;64:225-232.

28 McIntyre S, Badawi N, Brown C, Blair E: Population case-control study of cerebral palsy: neonatal predictors for low-risk term singletons. Pediatrics 2011;127:e667-e673.
29 Wyatt JS, Gluckman PD, Liu PY, Azzopardi D, Ballard R, Edwards a D, et al: Determinants of outcomes after head cooling for neonatal encephalopathy. Pediatrics 2007;119:912921.

30 Ambalavanan N, Carlo WA, Shankaran S, Bann CM, Emrich SL, Higgins RD, et al: Predicting outcomes of neonates diagnosed with hypoxemic-ischemic encephalopathy. Pediatrics 2006;118:2084-2093.

31 Anderson ME, Longhofer TA, Phillips W, McRay DE: Passive cooling to initiate hypothermia for transported encephalopathic newborns. J Perinatol 2007;27:592-593.

32 Hallberg B, Olson L, Bartocci M, Edqvist I, Blennow M: Passive induction of hypothermia during transport. Acta Paediatr 2009;98: 942-946.

33 Kendall GS, Robertson NJ, Azzopardi DV: Transport of infants referred for cooling treatment 2009 (accessed Oct 16, 2012). https://www.npeu.ox.ac.uk/tobyregister/ transport.

34 Daetwyler K, Brotschi B, Berger TM, Wagner BP: Feasibility and safety of passive cooling in a cohort of asphyxiated newborn infants. Swiss Med Wkly 2013;143:w13767.

-35 Martín-Ancel A, García-Alix A, Gayá F, Cabañas F, Burgueros M, Quero J: Multiple organ involvement in perinatal asphyxia. J Pediatr 1995;127:786-793.

-36 Shah P, Riphagen S, Beyene J, Perlman M: Multiorgan dysfunction in infants with postasphyxial hypoxic-ischaemic encephalopathy. Arch Dis Child Fetal Neonatal Ed 2004; 89:F152-F155.

37 Simbruner G, Nanz S, Fleischhacker E, Derganc $\mathrm{M}$ : Brain temperature discriminates between neonates with damaged, hypoperfused, and normal brains. Am J Perinatol 1994;11: 137-143

38 Singer D: Neonatal tolerance to hypoxia: a comparative-physiological approach. Comp Biochem Physiol A Mol Integr Physiol 1999; 123:221-234.

39 Gluckman PD, Hanson MA, Spencer HG: Predictive adaptive responses and human evolution. Trends Ecol Evol 2005;20:527-533.

40 Westin B: Hypothermia in the resuscitation of the neonate: a glance in my rear-view mirror. Acta Paediatr 2006;95:1172-1174.

41 Nei M, Glazko G V: The Wilhelmine E. Key 2001 Invitational Lecture. Estimation of divergence times for a few mammalian and several primate species. J Hered 2002;93:157-164. 